\title{
Indicadores Antecedentes para o Rio Grande do Sul
}

\section{Leading Indicators for Rio Grande do Sul}

\author{
Regis Sandrin* \\ Igor A. C. Morais**
}

\begin{abstract}
Resumo: Este artigo propõe a construção de indicadores antecedentes compostos com frequência mensal para a atividade econômica do estado do Rio Grande do Sul com base na metodologia da OCDE. Partindo de um universo de 456 diferentes séries de dados selecionou-se um conjunto de dez com potencial estatístico e características econômicas para anteceder o ciclo dos negócios. Os indicadores de longo-prazo se mostraram demasiadamente instáveis, os de médio prazo apresentaram desempenho satisfatório, conseguindo antecipar a maior parte dos turning points. Os melhores resultados foram percebidos no indicador que combina séries de médio e longo prazo.
\end{abstract}

Palavras-chave: Indicadores antecedentes. Ciclo dos negócios. Rio Grande do Sul.

\begin{abstract}
This paper propose a composite leading indicators at monthly periodicity to represent the economic activity in the state of Rio Grande do Sul based on OECD methodology. We start with 456 different time series data and selected a set of ten with potential statistical and economic characteristics to anticipate the business cycle. The long-term indicators proved too unstable, but the medium-term one showed satisfactory performance anticipating the majority of turning points. The best results were seen in the composite indicator that combines medium and long term series.
\end{abstract}

Keywords: Leading indicators. Business cycles. Rio Grande do Sul.

JEL Classification: E32; C32; C50.

\section{1 lntrodução}

Uma forma de se representar de maneira sucinta o comportamento agre-gado da economia em determinado momento é avaliando o Produto Interno Bruto (PIB). Porém, o mesmo possui diversas limitações de natureza temporal uma vez que, para vários países, é construído em base trimestral e, para muitos estados ou regiões só está disponível em periodicidade anual. Além disso, sua divulgação

\footnotetext{
* $\quad$ Mestre em Economia pela Universidade do Vale do Rio dos Sinos (Unisinos). E-mail: sandrin@ terra.com.br

* * Professor do Programa de Pós Graduação em Economia da Universidade do Vale do Rio dos Sinos (Unisinos). Pesquisador CNPq. Sócio-diretor da Vokin Investimentos. E-mail: imorais@unisinos.br
} 
ocorre com grande defasagem da data de referência ${ }^{1}$, tornando seu uso restrito quando o objetivo é ter um indicador amplo e que possa ter uma resposta mais conjuntural.

Uma alternativa para saber o estado da economia em tempo real é usar como proxy a combinação de diferentes variáveis macroeconômicas ${ }^{2}$. Essa combinação pode tanto ser útil para representar a situação atual, no que se denominam como indicadores coincidentes, como também para previsão, como os indicadores antecedentes ou então, defasados.

A literatura acerca da avaliação de indicadores compostos, sejam esses coincidentes ou antecedentes, tem estreita relação com a teoria dos ciclos dos negócios. Os primeiros estudos nessa área remontam ao século XIX. Desde então, diversas formulações teóricas passaram a ser construídas para explicar tal comportamento, inicialmente através de fatores exógenos, como guerras e secas, passando posteriormente para explicações endógenas, como a variação dos investimentos ou ciclos de inovações ${ }^{3}$. Paralelamente, uma corrente pragmática formou-se no inicio do século XX nos Estados Unidos, buscando, através da observação e análise econométrica das séries históricas, construir proxies para indicadores coincidentes, antecedentes e indicadores defasados ${ }^{4}$.

Desde a década de 1980, a OCDE desenvolve e publica mensalmente um indicador antecedente composto, denominado de Composite Leading Indicator (CLI), com base na metodologia dos ciclos de crescimento. Essa proposta é diferente da abordagem do ciclo econômico clássico, por considerar esses como variações em torno de uma tendência de longo prazo.

Além dos indicadores de países da OCDE, existem esforços também para a construção de indicadores para grupos de países (ZARNOWITZ et al., 2008; FORNI et al., 2001; GALLARDO; PEDERSEN, 2007); para determinados setores ou variáveis de uma economia (CHAUVET, 2000; CAULLIRAUX, 2007; CHAUVET; MORAIS, 2009); e para unidades territoriais menores, como estado ou região de um país (MORAIS; FRAINER, 2005; MORAIS; PORTUGAL, 2008; MORAIS, 2009).

Como forma de complementar a literatura na área, o presente artigo utiliza a metodologia da OCDE para construir indicadores antecedentes dos ciclos de crescimento da atividade econômica do Estado do Rio Grande do Sul. Para tanto, está dividido em três capítulos:

1 A data de divulgação do PIB oscila entre os diversos institutos de estatística no mundo entre 30 e 45 dias após o término do trimestre. Além disso, vários desses ainda promovem duas ou três revisões posteriores.

2 Croux et al. (2001) e Altíssimo et al. (2010) discutem a importância na construção de indicadores compostos.

3 Uma boa discussão sobre esse ponto pode ser vista em Zarnowitz (1984; 1992; 1999; 2001) e Mitchell (1988).

4 Atualmente os Estados Unidos dispõem de um sistema consolidado para datar e prever seus ciclos econômicos e que foi originado no National Bureau of Economic Research (NBER). 
a) uma revisão bibliográfica sobre o tema;

b) a descrição da metodologia utilizada na construção dos indicadores;

c) a análise dos dados e discussão dos resultados.

\section{Ciclos e Indicadores Antecedentes}

Diferentemente dos conceitos teóricos, o conhecimento popular a respeito de ciclos econômicos é fundamentado em experiências históricas, onde são identificados períodos de prosperidade e depressão. O ponto de virada entre esses dois períodos, também denominado na literatura da área de turning point, é caracterizado por um pico ou vale.

Talvez o primeiro a constatar o comportamento ondulatório em torno de uma tendência de longo prazo das séries agregadas tenha sido Juglar em 1862. $\mathrm{O}$ autor investigou as causas e os efeitos das crises comerciais que ocorreram na Europa e nos Estados Unidos durante o século XIX. Uma parte da literatura na área trabalha com a percepção de que seus movimentos são característicos de diversas variáveis econômicas. Nesse ponto, assume-se a existência de relações regulares entre variáveis estratégicas, como preços, custos e lucros, e que contribuiu para posteriormente ser desenvolvida uma metodologia paramétrica para indicadores coincidentes, antecedentes e defasados ${ }^{5}$.

O ponto de partida nesse processo é a definição de uma série de referência no qual se procura antecipar o movimento cíclico. A partir dessa, a proposta de Burns e Mitchell (1946) é construir um sistema de indicadores segregando-os em três grupos distintos de acordo com sua reação temporal. O primeiro é definido como Indicadores Coincidentes, e tem como característica o fato de que o movimento das diversas variáveis econômicas que o compõem, acompanham contemporaneamente os movimentos da série de referência. O segundo grupo é denominado de Indicadores Antecedentes e agrega diversas variáveis cujos movimentos se antecipam à série de referência do ciclo. Nesse caso, podem ser caracterizados como variáveis de previsão. Por fim há um terceiro grupo de variáveis que podem ser classificadas como Indicadores Defasados. Para esses, seus movimentos cíclicos se dão posteriormente aos da série de referência. Apesar de ser pouco útil para os propósitos de previsão, a observação dos indicadores defasados é útil para confirmar ou retificar o que está sendo apontado pela variável alvo.

Portanto, tal como sugerido na literatura, um sistema de indicadores completo é composto de quatro grupos de séries: a série de referência, os antecedentes, coincidentes e os defasados. A série de referência é apenas uma. Mas, os demais indicadores podem ser construídos a partir de uma única variável, ou então, a partir da combinação de diversas variáveis individuais, resultando em indicadores

5 Diebold e Rudebusch (1996) e Milas et al. (2006) discutem essa aplicação. 
compostos. É comum na literatura fazer uso de diversos indicadores, uma vez que esse contribui para diminuir erros que são mais frequentes quando se concentra a atenção no comportamento de apenas uma variável ${ }^{6}$.

Entre as características dos primeiros sistemas de indicadores antecedentes, algumas se destacam por permearem a discussão recente sobre o tema. A principal é que o foco destes indicadores não seria prever valores futuros das séries econômicas de referência e sim apenas antecipar os pontos de reversão do ciclo econômico, como apontado por Campelo (2008).

Atualmente, existem dois grandes métodos institucionalizados e utilizados mundialmente para a construção de sistemas de indicadores antecedentes. $\mathrm{O}$ primeiro teve origem nos Estados Unidos, que dispõe de um sistema consolidado para datar e prever seus ciclos econômicos e que foi gestado no National Bureau of Economic Research (NBER).

Neste método, os objetos de previsão são os pontos de reversão do ciclo, ou seja, quando há mudança entre picos e vales. Na literatura da área esses pontos são conhecidos como turning points. Como pode ser visto, este sistema sinaliza somente alguns momentos do ciclo econômico, e não sua trajetória inteira. Assim, uma eventual aceleração ou desaceleração do crescimento não é captada pelo indicador antecedente, uma vez que isto não implicaria em mudança no sinal da variável de referência.

No segundo método de indicadores antecedentes, a abordagem é feita a partir dos ciclos de crescimento e é utilizada pela OCDE na construção de indicadores para diversos países. Nesta abordagem as flutuações seriam medidas como desvios em relação à tendência de longo prazo dos agregados econômicos, representando mudanças na taxa de crescimento. Os ciclos de crescimento ocorrem com maior frequência e seriam mais simétricos que os ciclos clássicos, uma vez que todas as recessões envolvem uma desaceleração da economia, mas nem todas as desacelerações implicam em recessões ${ }^{7}$. Uma alegada vantagem desta abordagem é que as variáveis expressas como desvios da tendência de longo prazo representariam diretamente o hiato do produto, isto é, a diferença entre a taxa de crescimento corrente e a taxa de crescimento do Produto Interno Bruto (PIB) potencial.

Uma diferença importante entre os dois métodos é a própria definição de ciclo econômico. O método criado pelo NBER utiliza o conceito de ciclo em termos da variação do nível absoluto do produto, sendo uma recessão definida pela queda continuada do nível do PIB e que se torna visível em algumas variáveis relevantes, como a produção industrial, o emprego, a renda real e as vendas do comércio. Por outro lado, a OCDE parte do pressuposto que a economia exibe

\footnotetext{
6 Ver OECD (2008b) para uma discussão sobre a metodologia de construção de indicadores compostos.

7 Ver Nilsson e Brunet (2006), Zarnowitz (2001) e Lima (2005).
} 
um padrão de crescimento positivo no longo prazo. Devido a essa tendência, períodos de contração da economia podem não se manifestar como uma queda absoluta no PIB, e sim, apenas implicar em um crescimento abaixo da tendência de longo prazo. Já o período de auge, seria aquele em que o crescimento é acima desta mesma tendência. Por esse motivo, o método da OCDE exige também um cálculo estatístico para a tendência de crescimento da economia, o qual constitui o ponto de referência da análise ${ }^{8}$.

Atualmente a literatura internacional a respeito de indicadores antecedentes é extensa, e muitos estudos utilizam técnicas econométricas das mais diversas (STOCK; WATSON, 1988; 1989; 1991; 1993; 1998; 2003; 2005; HAMILTON, 1989; 1990; 1991; 1996; CHAUVET, 2000; 2002; AGUIRRE; CÉSPEDES, 2004; GALLARDO; PEDERSEN, 2007; LIMA, 2007; CAMPELO, 2008; CHAUVET; MORAIS, 2009).

Há diversas aplicações para grupo de países, como por exemplo, em Zarnowitz et al. (2008) que considera o conceito de ciclo econômico clássico e construiu indicadores antecedentes e coincidentes compostos para a Zona do Euro. Forni et al. (2001) também avaliaram os países da zona do Euro e construíram indicadores antecedentes e coincidentes conciliando análise de componente principal e fator dinâmico.

Na América Latina, apesar dos esforços recentes, não existe tradição na construção destes indicadores. Talvez um dos motivos para essa limitação seja a instabilidade econômica da região durante os anos 70 e 80 e, também, pela ausência de séries históricas com maior horizonte temporal ${ }^{9}$.

Esforços recentes podem ser vistos nos trabalhos de Aguirre e Céspedes (2004), para o Chile e Gallardo e Pedersen (2007) que desenvolveram um sistema para os países da região usando abordagem semelhante a proposta pela OCDE. Em seu estudo, aos autores criaram indicadores antecedentes nacionais e, posteriormente, indicadores compostos para três grupos de países: o primeiro grupo com Brasil, México e Argentina; o segundo com as sete maiores economias regionais e; finalmente, um índice com onze países. $\mathrm{O}$ indicador antecedente composto pelas sete maiores economias da região consegue representar muito bem os ciclos econômicos, porém, o mesmo não ocorre utilizando-se apenas o primeiro grupo.

No Brasil, a produção sobre indicadores antecedentes, coincidentes e defasados foi muito pequena até meados da década de 70. A partir de então o interesse passou a ser crescente em especial após a estabilização econômica em meados dos anos 90.

Contador (1977) elaborou índices para a atividade econômica no Brasil, pautando-se no sistema desenvolvido pelo NBER e utilizando outras metodo-

8 Estrella (2007) e Nilsson e Gyomai (2008) fazem uma comparação entre diferentes formas de se extrair a tendência cíclica de uma série de tempo.

9 As interrupções na divulgação de séries históricas, bem como a constante mudança metodológica na maioria dos países da América Latina, acabam por limitar essa investigação. 
logias como análise de componentes principais. Chauvet (2000) construiu indicadores antecedentes para a inflação brasileira utilizando um modelo de mudança estocástica periódica de regime markoviano para determinar os turning points do IPCA e, em seguida, um modelo de fator dinâmico para extrair movimentos cíclicos comuns em uma série de variáveis que apresentam conteúdo preditivo da variação de preços.

Chauvet (2002), também modelou o PIB a partir de uma tendência, seguindo uma cadeia de Markov não observável de dois estados - recessão e expansão com dados de 1980 a 2000. Concluiu que os resultados poderiam ser utilizados como ponto de referência para a avaliação da atividade econômica.

Lima (2005) utilizou quatro metodologias para o caso brasileiro, o Modelo de indicadores antecedentes tal qual a proposta do NBER, o Modelo Autorregressivo de Defasagem Distribuída (ARDD), modelo de componentes principais e vetores autorregressivos. Os resultados, com séries a partir de 1975, sugerem que há possibilidade de montar um sistema completo de indicadores para o Brasil com bons resultados no acompanhamento do PIB. Caulliraux (2007) aplicou a metodologia do NBER para construir indicadores para o PIB e a indústria de construção civil brasileira.

Campelo (2008) produziu uma comparação, para o caso brasileiro, entre três metodologias de construção de indicadores antecedentes:

a) a abordagem tradicional do NBER e da OECD;

b) a seleção de variáveis por meio de teste de casualidade de Granger; e

c) a seleção e pesos determinados por meio de regressão múltipla. Segundo o autor a abordagem por ciclos de crescimento, como proposto pela OCDE, seria mais estável para as características locais em relação à abordagem em níveis absolutos do produto.

Morais e Portugal (2009) aplicam mudança de regime markoviano proposta por Hamilton (1989) para identificar os fatos estilizados do ciclo dos negócios da produção industrial nos principais estados brasileiros. Chauvet e Morais (2009) constroem modelos antecedentes para previsão da indústria de bens de capital no Brasil através de um modelo probit com dinâmica autorregressiva. Morais (2009) compara os métodos de datação de cliclos de Bry e Boschan (1971) e Hamilton (1989) além de criar um indicador antecedente composto para a atividade industrial no estado do Rio Grande do Sul.

Como pode ser visto, há diversas iniciativas para o desenvolvimento de sistemas de indicadores para países da América Latina e, especialmente no Brasil. Porém, devido a sua vasta aplicabilidade no estudo de ciclos e previsão dos mesmos, seja para regiões ou então diferentes setores de atividade econômica, pode- 
se inferir que, relativamente ao observado na literatura internacional, ainda há um vasto campo de pesquisa para ser explorado no Brasil.

\section{Metodologia}

A metodologia da OCDE para a construção de indicadores antecedentes, e que será utilizada nesse artigo, propõem quatro procedimentos em diferentes etapas, resumidos no Quadro 1 e descritos a seguir ${ }^{10}$.

O primeiro passo é definir a série de referência a ser antecipada. Quando o objetivo é avaliar o agregado da economia, o mais recomendado na literatura internacional é o PIB. Contudo, devido as suas limitações de ordem temporal é comum usar a produção industrial para descrever o comportamento cíclico da economia. Apesar de sua maior volatilidade, diversos estudos identificam que seus ciclos coincidem bem com os picos e vales do PIB, ver OECD (2008a; 2008b), para uma avaliação a países da OCDE e Campelo (2008), que em estudo semelhante realizado para a economia brasileira, encontrou relação cíclica entre o PIB e a produção industrial. No caso do presente artigo, dada a limitação de dados em frequência mensal e também trimestral em um espaço mais longo de tempo para o PIB, será utilizada a Produção Industrial do Rio Grande do Sul como proxy dos ciclos da série de referência.

Quadro 1 - Procedimentos para construção dos indicadores antecedentes compostos

\begin{tabular}{|c|c|c|}
\hline & Procedimento & Ferramenta utilizada \\
\hline & Selecionar a série de referência & - \\
\hline 1 & $\begin{array}{l}\text { Escolha das séries que são candidatas a } \\
\text { antecedentes. Divisão de acordo com } \\
\text { razão econômica }\end{array}$ & $\begin{array}{l}\text { 1. Estágio primário } \\
\text { 2. Resposta rápida } \\
\text { 3. Sensíveis à expectativa } \\
\text { 4. Causadores primários }\end{array}$ \\
\hline 2 & Filtragem & $\begin{array}{l}\text { 1. Dessazonalização } \\
\text { 2. Extração da tendência cíclica } \\
\text { 3. Verificação da presença de outliers } \\
\text { 4. Padronização das séries }\end{array}$ \\
\hline 3 & Identificação das correlações cíclicas & $\begin{array}{l}\text { 1. Correlação cruzada } \\
\text { 2. Causalidade de Granger } \\
\text { 3. Algoritmo de Bry-Boschan(1971) }\end{array}$ \\
\hline 4 & Indicador composto & 1. Agregação \\
\hline
\end{tabular}

Fonte: Elaboração própria.

10 Uma descrição detalhada dos procedimentos pode ser vista em OECD (2008a; 2008b). 
A seguir, ainda dentro do primeiro passo, é feita uma investigação sobre as séries que são candidatas a anteceder os ciclos da série de referência. O processo de seleção dessas é feito a partir de uma divisão do maior número de séries possíveis em dois tipos de acordo com suas características. No primeiro é avaliada sua relevância considerando questões como: (i) a significância econômica das mesmas a partir de um ponto de vista da teoria econômica ${ }^{11}$; (ii) a amplitude de cobertura, onde as séries que representam a atividade econômica de forma mais ampla são preferíveis em relação as mais restritas.

O segundo tipo considera os critérios práticos. Nesse caso, avaliam-se: (i) a frequência temporal das séries, onde as mensais são preferíveis àquelas trimestrais; (ii) as revisões a que as mesmas são submetidas, ou seja, prefere-se aquelas com menos mudanças metodológicas ao longo do tempo; (iii) as atualizações, ou seja, a publicação dos dados deve ocorrer logo após o período à qual estes se referem e; (iv) a duração, onde séries mais longas e sem interrupções são preferíveis.

Após essa investigação primária, os respectivos indicadores antecedentes potenciais podem ser classificados em quatro tipos de razões econômicas para sustentar sua fundamentação: (i) Estágios Primários: Indicadores que mensuram estágios primários da produção, como encomendas à indústria; licenciamento de construções, etc.; (ii) Resposta Rápida: Indicadores que respondem rapidamente a mudanças na atividade econômica, como média de horas trabalhadas, lucros e estoques; (iii) Sensíveis a Expectativas: que são os indicadores que mensurem, ou, sejam sensíveis a expectativas, como o preço das ações, cotações de matériasprimas e índices de expectativas e de confiança baseados em surveys; (iv) Causadores Primários: que contempla os indicadores relativos à política monetária e desenvolvimento econômico, como estoque de moeda e termos de troca.

Após essa etapa, o segundo passo consiste em remover as características que podem interferir no processo de previsão, como por exemplo, a sazonalidade, outliers, tendência e demais ruídos. Esse passo pode ser entendido como um processo de "suavização" dos dados ${ }^{12}$.

Ainda dentro do processo de suavização, são identificados os padrões cíclicos subjacentes de todas as séries. Para isso, é necessária a remoção de dois fatores: tendência de longo prazo e os ruídos de alta frequência. O presente estudo utilizou, em detrimento do filtro PAT, comumente utilizado pela OECD, o filtro HP e $\mathrm{CF}$, devido a sua maior aderência, conforme demonstrado pelo estudo de Nilsson e Gyomai (2008).

11 Por exemplo, a produção industrial de papel, papelão e embalagens é uma série que possui, naturalmente, características antecedentes.

12 Outro ponto importante está relacionado à periodicidade. Geralmente os indicadores compostos são construídos para publicação mensal, entretanto há séries com publicação trimestral que necessitam de conversão para frequência mensal. Nesse caso, pode-se fazer uso de métodos de interpolação. 
Outro ponto importante nessa etapa é a padronização das séries. Isso deve ser feito como forma de eliminar as distorções causadas pelas diferentes medidas escalares que cada uma possui. Neste caso, após a eliminação dos padrões sazonais, da tendência de longo prazo e dos ruídos de alta frequência, subtrai-se das mesmas suas médias, e o resultado é dividido pelo desvio padrão. A seguir, para manter a mesma escala, adiciona-se o valor 100.

A partir desse ponto podemos identificar os padrões cíclicos no conjunto de dados. Primeiramente, é verificado o tempo transcorrido entre os pontos de inversão. Como esse tempo pode ter diferentes periodicidades, o procedimento mais usual é separar esses resultados em dois grupos de acordo com a distância temporal: (i) até seis meses convencionou-se denominar de médio prazo; (ii) acima de seis meses, de longo prazo.

Uma técnica estatística útil para obter essa informação é a correlação cruzada, feita dois a dois, ou seja, a série de referência é comparada com cada uma das demais para identificar em que período essa correlação é maior. Destaca-se que o local de pico da função de correlação cruzada é um bom indicador alternativo do tempo de antecedência médio. Se essa correlação for contemporânea, então o indicador avaliado é classificado como coincidente. Por outro lado, se o pico da correlação cruzada for negativo, então o mesmo é classificado como antecedente e, por fim, se for positivo, como defasado.

Neste artigo, além da técnica da correlação cruzada para identificar a relação cíclica entre as diversas séries e a de referência, utilizaram-se também mais dois métodos de filtragem. Primeiramente, tal como no trabalho de Campelo (2008), usou-se a causalidade de Granger. Além disso, as séries que apresentaram resultados significativos nos testes de correlação cruzada e causalidade de Granger foram selecionadas para serem submetidas ao algoritmo de Bry-Boschan, tal como no estudo de Morais (2009), datando os respectivos ciclos de negócios das mesmas, ou seja, encontrando os turning-points e, posteriormente, comparando os mesmos. Essa avaliação contribui para definir, a partir de um universo amplo de séries, o grupo daquelas que apresenta os melhores resul-tados para serem consideradas como antecedentes.

Uma característica importante nos resultados é que as séries componentes selecionadas também não devem "perder" nenhum ciclo econômico ou apresentar ciclo adicionais em relação a série de referência. Se isso ocorrer, as chances delas preverem ciclos inexistentes, ou mesmo de deixar de prever ciclos, aumentam consideravelmente, prejudicando a eficácia do indicador final.

Por fim, de posse das séries antecedentes, o passo seguinte é agregar as mesmas como forma de obter um indicador composto. Salienta-se que algumas séries podem apresentar comportamento contracíclico (inverso) em relação à série de referência. Porém, tal característica pode ser útil na construção de indicadores compostos. 


\section{Análise dos Dados}

A literatura na área de estudos de indicadores antecedentes aponta as dificuldades e deficiências em usar o PIB como série de referência. No Rio Grande do Sul há um indicador coincidente da atividade econômica construído pelo Banco Central do Brasil, IBCR-RS, e que pode ser usado como proxy do PIB em periodicidade mensal. Entretanto, seu horizonte de tempo, com início em janeiro de 2002, é demasiado curto para a datação dos ciclos e avaliação da eficácia dos indicadores antecedentes.

A alternativa natural é a série "Produção industrial do RS geral"13. A mesma tem frequência mensal e o período analisado vai de janeiro de 1991 e abril de 2010 , em um total de 231 meses. Como pode ser visto no Gráfico 1, quando avaliado a partir de 2002, o ciclo da produção industrial e do IBCR-RS apresenta característica temporal muito semelhante, com uma correlação de 0,84 . Isso reforça a percepção de que a produção industrial pode ser considerada uma boa proxy para os movimentos cíclicos da economia gaúcha, com a vantagem de ter mais informações no tempo ${ }^{14}$.

Gráfico 1 - Comportamento Cíclico IBCR-RS e Prod. Industrial RS

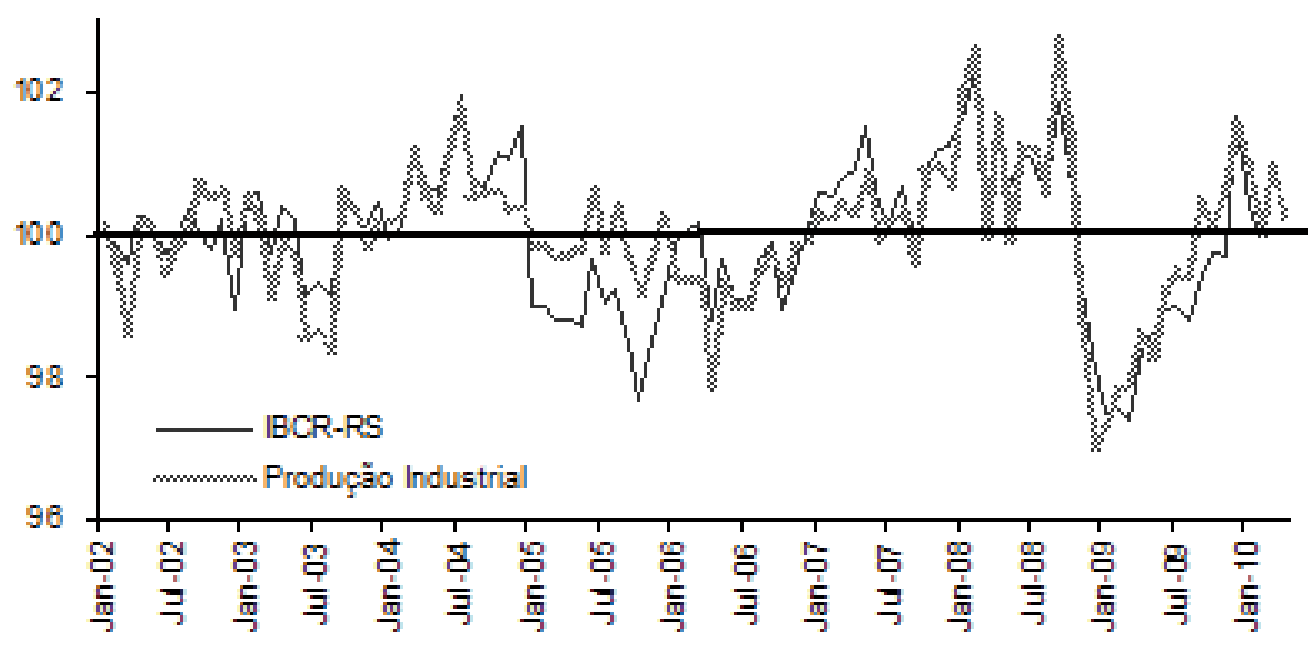

Fonte: IBGE e BCB.

A seguir, como forma de datar o ciclo dos negócios, foi aplicado o algoritmo de Bry-Boschan (1971) para a série da Produção Industrial. Esse é mostrado no Gráfico 2, onde é possível identificar seis recuperações, denominadas as fases de expansão, e seis recessões, denominadas de contrações. Esses períodos recessivos estão assinalados com barras de cor cinza, e suas respectivas datas mostradas na Tabela 1.

13 Disponibilizada pelo IBGE em sua tabela 2295.

14 Foi feito o ajuste sazonal pelo método X-12 e aplicado o filtro HP em ambas as séries. Posteriormente, as mesmas foram normalizadas. 
Gráfico 2 - Ciclos Econômicos do RS

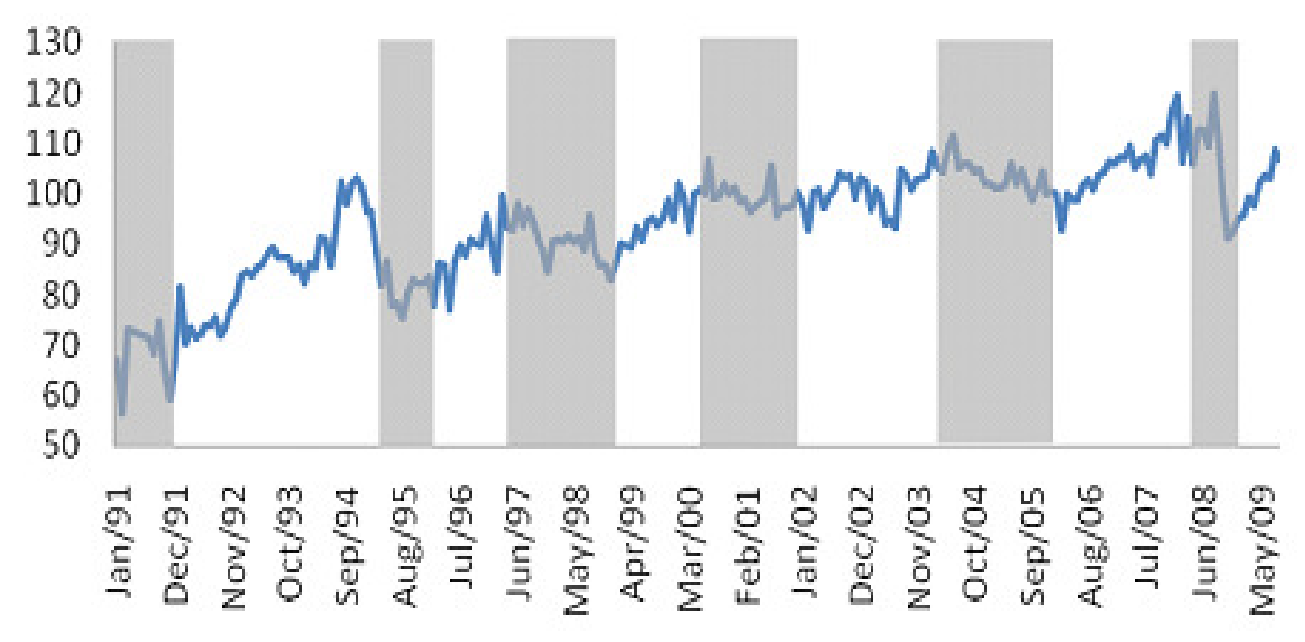

Fonte: IBGE.

O período recessivo mais longo foi entre março de 2004 e janeiro de 2006 e pode estar diretamente ligado aos efeitos adversos que a seca teve sobre a economia do estado (MORAIS, 2009). No geral, as recessões na economia gaúcha tiveram uma duração média de 16 meses alternada com períodos de recuperação com duração média de 24 meses. Assim, um ciclo médio total, de pico a pico, pode ter uma duração média de 41 meses.

Tabela 1 - Datação e duração dos Ciclos Econômicos no RS

\begin{tabular}{cccc}
\hline $\begin{array}{c}\text { Duração das } \\
\text { fases de expansão } \\
\text { (meses) }\end{array}$ & Início da Recessão & Final da Recessão & $\begin{array}{c}\text { Duração das fases } \\
\text { de contratações } \\
\text { (meses) }\end{array}$ \\
\hline- & - & $12-1991$ & - \\
39 & $03-1995$ & $02-1996$ & 11 \\
14 & $07-1997$ & $01-1999$ & 21 \\
16 & $05-2000$ & $12-2001$ & 19 \\
27 & $03-2004$ & $01-2006$ & 22 \\
27 & $04-2008$ & $01-2009$ & 9 \\
24,6 & Média & & 16,4 \\
\hline
\end{tabular}

Fonte: Elaboração própria.

Morais (2009) comparou três métodos de datação de ciclos para a mesma série: (i) Bry e Boschan (1971); (ii) Hamilton (1989); (iii) uma "regra de bolso" 15. $\mathrm{O}$ autor utilizou dados trimestrais identificando um ciclo recessivo a mais entre o

15 A "regra de bolso" consiste em caracterizar como recessão dois períodos consecutivos de queda no nível absoluto da variável. Porém, essa técnica pode ser considerada muito mais indicativa do que determinística para caracterizar uma recessão. 
terceiro trimestre de 2002 e o terceiro trimestre de 2003 relativamente às estimativas mensais realizadas neste estudo. Entretanto as outras recessões coincidem no tempo e em sua duração média, de 5,4 trimestres (16,2 meses). O quadro 2 mostra essas estimativas.

Quadro 2-Cronologia dos ciclos recessivos no RS

\begin{tabular}{|c|c|c|}
\hline Regra de bolso & Bry-Boschan (1971) & Hamilton (1989) \\
\hline 91-III a 91-IV & 94-IV a 95-III & 96-I a 96-I \\
\hline 93-IV a 94-I & 97-II a 99-I & 97-III a 98-II \\
\hline 95-I a 95-III & 00-III a 02-I & 98-IV a 99-I \\
\hline 97-IV a 98-I & 02-III a 03-III & 00-II a 00-II \\
\hline 98-IV a 99-I & 04-II a 06-II & 00-IV a 01-II \\
\hline 00-IV a 01-II & & 01-IV a 02-I \\
\hline 01-IV a 02-I & & 02-IV a 03-III \\
\hline 03-I a 03-III & & 04-III a 06-II \\
\hline 04-IV a 05-I & 06-IV a 06-IV \\
\hline 05-III a 06-II & 07-III a 07-III \\
\hline \multicolumn{2}{|c|}{ Média de duração dos ciclos recessivos (em trimestres) } \\
\hline 2,5 & & 08-II a 08-II \\
\hline
\end{tabular}

Fonte: Morais (2009).

Como forma de verificar o grau de aderência dos ciclos recessivos no Rio Grande do Sul com aqueles mensurados pela economia brasileira, os resultados aqui encontrados são comparados com as estimativas feitas pelo Comitê de Datação de Ciclos Econômicos (CODACE), e está descrito na Tabela 2. É possível verificar que o ciclo dos negócios do Rio Grande do Sul coincide, em grande parte, com os ciclos estimados para o Brasil. Entretanto, tanto neste estudo, quanto nos resultados de Morais (2009), foi datado um período recessivo na economia regional, entre 2004 e 2006, que não ocorreu no cenário nacional. 
Tabela 2 - Cronologia dos ciclos de negócios brasileiros (CODACE)

\begin{tabular}{cccccc}
\hline & & Recessões & Expansões & \multicolumn{2}{c}{ Ciclos } \\
\cline { 3 - 6 } Picos & Vales & \multicolumn{4}{c}{ Número de meses } \\
\cline { 3 - 6 } & & $\begin{array}{c}\text { De pico a } \\
\text { vale }\end{array}$ & $\begin{array}{c}\text { De vale a } \\
\text { pico }\end{array}$ & $\begin{array}{c}\text { De pico a } \\
\text { pico }\end{array}$ & $\begin{array}{c}\text { De vale a } \\
\text { vale }\end{array}$ \\
\hline Dez/94 & Set/95 & 9 & 36 & 66 & 45 \\
Out/97 & Fev/99 & 16 & 25 & 34 & 41 \\
Dez/00 & Set/01 & 9 & 10 & 38 & 31 \\
Out/02 & Jun/03 & 8 & 13 & 22 & 33 \\
Jul/08 & Jan/09 & 6 & 61 & 69 & 67 \\
Duração média no Brasil & 15,8 & 28,7 & 49,3 & 46,1 \\
\hline
\end{tabular}

Fonte: FGV (2010).

Nota: Para o cálculo da duração média do ciclo de negócios no Brasil, levou-se em conta todos os ciclos datados pelo CODADE desde 1980.

Ainda de acordo com o CODACE, a economia brasileira apresentou o maior período contínuo de expansão desde o início da datação dos ciclos de negócios feita em 1980, e que compreende o período entre junho de 2003 e janeiro de 2008, em um total de 61 meses. Esse período acabou por elevar a duração do ciclo econômico médio brasileiro de maneira a destoar o mesmo da média apresentada pelo Rio Grande do Sul. Entretanto, desconsiderando o mesmo cálculo, os dados do Estado também apresentam consistência com a duração média dos ciclos econômicos com a economia brasileira.

O passo seguinte à definição da série de referência e a datação de seus ciclos, é a investigação de quais variáveis podem antecipar esses movimentos. Inicialmente foram consideradas 456 séries de diversas fontes de dados e periodicidade. As mesmas foram sujeitas a uma pré-seleção de acordo com os critérios práticos citados na seção 3, resultando na manutenção apenas das séries com frequência mensal, sem interrupções ${ }^{16}$ e que tivessem sua publicação ocorrendo com no máximo um mês de defasagem em relação à publicação da série de referência ${ }^{17}$. A seguir também foram eliminadas as séries seguindo critérios quanto à relevância econômica. Essa pré-seleção resultou na classificação de apenas 168 séries.

16 A exceção foi a série "Expedição de caixas, acessórios e chapas - papelão ondulado - Tonelada - ABPO", que apresentava uma interrupção de 4 meses, e a série "Utilização da capacidade instalada - indústria - média - (\%) - FGV/Conjuntura Econômica”, que inicialmente era trimestral e depois passou a ser publicada com frequência mensal. Para tais séries, foi utilizado o método de interpolação cardinal spline para a estimação dos valores faltantes.

17 A Produção industrial é publicada 45 dias após o encerramento do período de referência. Sendo assim, logo neste estudo foram utilizadas apenas séries que fossem publicadas em até 75 dias após sua ocorrência. 
Posteriormente, foi feita a filtragem dessas séries retirando-se os efeitos sazonais e a tendência cíclica via filtros Hodrick-Prescott e Christiano-Fitzgerald ${ }^{18}$. Com isso foram obtidas duas informações sobre o componente cíclico de cada série pré-selecionada que, somadas às informações da série de referência, totalizou 338 séries. A seguir, cada uma foi normalizada.

A verificação da concordância cíclica entre a série de referência e cada uma das 168 séries candidatas a antecedentes foi feita a partir de dois critérios: (i) correlação cruzada ${ }^{19}$; (ii) teste de causalidade de Granger ${ }^{20}$. Os resultados apontaram para um total de 60 séries como sendo fortes candidatas a indicadores antecedentes. A seguir, cada uma dessas 60 foi submetida ao algoritmo de Bry-Boschan (1971), para a caracterização dos turning points, ou seja, as datas dos picos (peaks), que correspondem às datas de início das contrações e as datas dos vales (through), que correspondem ao ponto de inflexão das séries entre um período de contração e outro de expansão. Com esses resultados foi possível verificar quais apresentaram coincidência ou então antecedência com os ciclos de referência, complementando a análise anterior.

Após essa relação, o total de séries reduziu-se a 31, e que possuem um ou mais pontos de inflexão coincidentes com a série de referência, sendo que houve ocorrência de coincidência em 13 picos e 29 vales. Dessa análise, três séries se destacam, pois apresentam coincidência em 3 pontos de inflexão cada: (i) "Sondagem Industrial Geral - Índice de Confiança da Indústria, divulgado pela FGV; (ii) "Indicadores Industriais do Rio Grande do Sul - Bens Intermediários - Compras totais, divulgado pela FIERGS" e (iii) Indicadores Industriais do Rio Grande do Sul - Bens Intermediários - Horas Trabalhadas, divulgada pela FIERGS.

Para a análise da antecedência dos pontos de inflexão em relação à série de referência, foi estabelecido um critério de ponto de corte. Aqueles que fossem antecipados em até 6 meses, eram considerados de médio prazo e, os antecipados entre 7 e 12 meses, de longo prazo. Dentro desses critérios, 80 pontos de inflexão foram antecipados como de médio prazo, sendo 22 picos e 58 vales. Já no longo prazo, 30 pontos de inflexão foram antecipados, sendo 15 picos e 15 vales.

Sendo assim, nove séries apresentaram bons resultados para a antecipação dos turning points no médio prazo, especialmente os vales, sendo que quatro anteciparam três pontos de inflexão. Outras quatro anteciparam quatro pontos e uma antecipou cinco pontos de inflexão no médio prazo. No longo prazo, sete séries apresentaram desempenho destacado, prevendo dois pontos de inflexão. Cabe

18 Não há consenso na literatura da área sobre o uso do filtro HP para extração da tendência cíclica. Uma discussão sobre sua aplicação e comparação com outros métodos pode ser vista em Nilson e Gyomai (2008), Cogley e Nason (1995) e Teles et al. (2005).

19 Neste teste, foram analisados até 32 antecedentes (leads) e defasagens (lags).

20 Os testes de Granger foram realizados para 3, 6, 12, 24 e 36 meses de defasagem. 
ainda destacar que algumas apresentaram antecipação de médio e de longo prazo simultaneamente, apresentando até um total de seis antecipações.

Com base em todos os testes acima mencionados, dez séries foram selecionadas como candidatas a Indicadores Antecedentes sendo as mesmas listadas no Quadro 3.

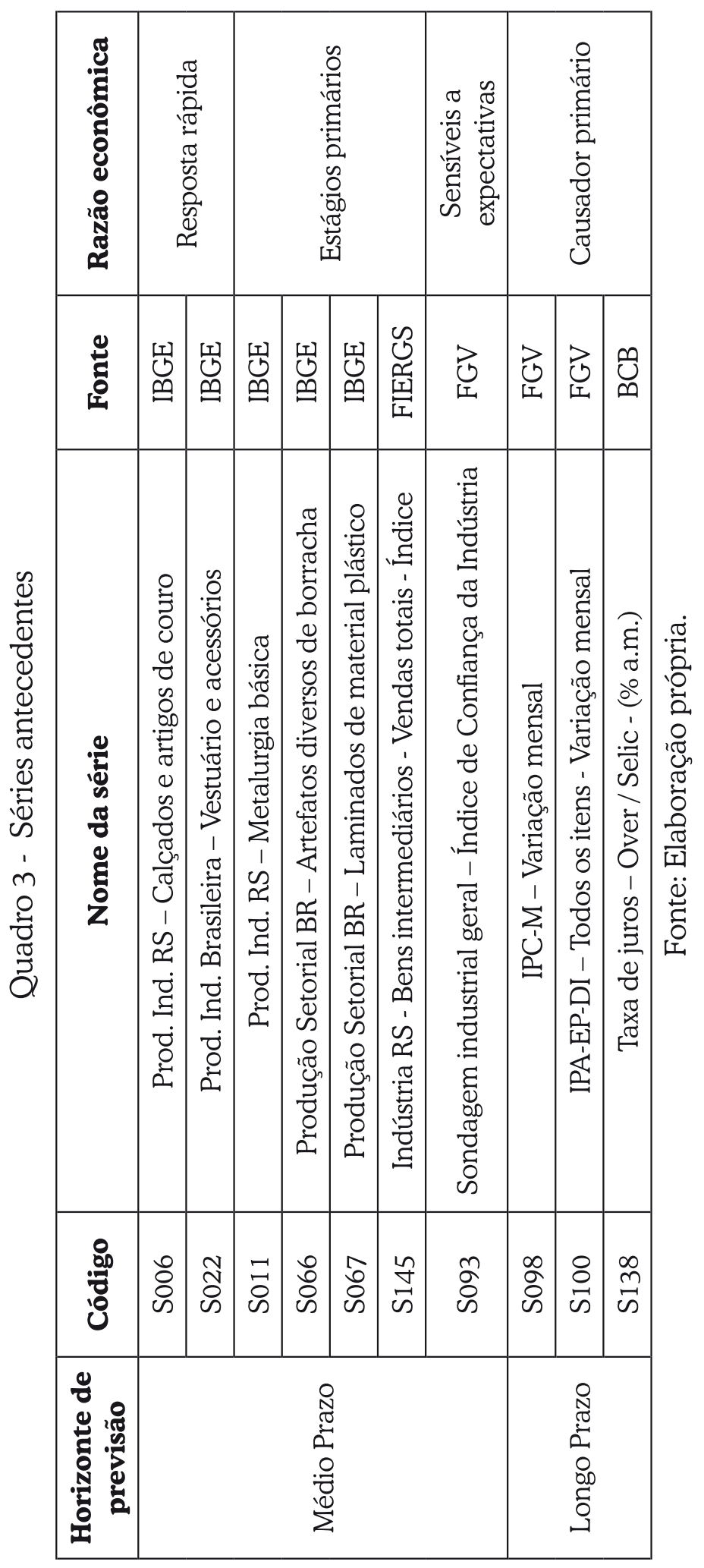


Um resultado interessante a observar é a correspondência que existe entre o horizonte de previsão de médio prazo e o fato dessas séries terem, como razão econômica, três funções: resposta rápida, estágios primários e sensiveis à expectativa. No longo prazo estão aquelas que têm como razão o causador-primário.

Assim, dentre as séries componentes há representantes de todos os quatro grupos de razões econômicas propostos pela OCDE para sustentar sua fundamentação, como apontado na seção 3, o que sugere que existe material para a construção de um indicador composto robusto. Duas séries, a de número S006 e a S022 representam setores da indústria com bastante sensibilidade ao momento econômico e forte presença no estado do Rio Grande do Sul.

A primeira, a produção de calçados e artigos de couro, é um importante setor da indústria local e apresenta o mesmo número de recessões que a série de referência, sendo que, em três ocasiões, antecipa a crise e os pontos de retomada. Entretanto, em duas outras ocasiões, é possível notar que o ciclo econômico desta ocorre em períodos deslocados em relação à economia do estado. A segunda, a produção de vestuário e acessórios, representa outro setor significativo na indústria local. Assim como a produção de calçados, também apresenta o mesmo número de ciclos que a economia estadual. Porém, seu comportamento quanto à antecedência ou às defasagens dos pontos de inflexão não é uniforme. Destaca-se que em cinco turning points a mesma antecipa as viradas da série de referência e, em outros cinco, há uma defasagem.

Quatro séries, as de número S011, S066, S067 e S145, são setores ou categoria de uso das indústrias classificados como estágios primários de produção. A metalúrgica básica apresenta um comportamento cíclico mais uniforme em relação à série de referência. Seu comportamento antecedente se dá por representar um setor produtor de matéria-prima. Um ponto interessante no comportamento cíclico da mesma é que suas recessões iniciam, em média, com defasagem em relação a produção industrial, mas os períodos de recuperação iniciam, em geral, com antecedência em relação a série de referência. Neste caso, é de se esperar que sua presença no indicador composto aumente o poder de previsão dos vales.

A produção brasileira de artefatos de borracha, outra representante do grupo "estágios primários", por representar um grupo da indústria produtor de matérias-prima, não apresenta ciclos adicionais ou perdidos. Além disso, em nove dos pontos de inflexão analisados, cinco antecipam os pontos de virada da série de referência. A produção brasileira de laminados de material plástico, também uma série "estágio primário", perde dois ciclos, porém, dos seis turning points do período da série de referência, quatro são antecipados. As vendas da indústria de bens intermediários do Rio Grande do Sul apresentam o mesmo número de ciclos que a série de referência. Porém, a mesma não consegue antecipar a recessão 
identificada no Rio Grande do Sul entre 1999 e 2001 e, além disso, apresenta uma recessão a mais entre 2002 e 2004.

Uma série, a de número S093, é um indicador sensível a expectativa. O Índice de Confiança da Indústria se mostrou um bom indicador de médio prazo, apresentando o mesmo número de ciclos e, de um total de nove pontos de inflexão, antecipa cinco, além disto, dois coincidem. Cabe aqui destacar que séries de índices de confiança são recentes no Brasil e este é um dos estudos pioneiros a incluir séries dessa natureza na construção de indicadores antecedentes compostos.

Por fim, três séries são classificadas como causador-primário, as de número S098, S100 e S138, justamente por se tratarem de elementos de política monetária, como a taxa de juros ou então endógenos do ciclo. O IPC-M, IPA e Selic, aqui classificados como indicadores de longo prazo, apresentaram mais instabilidade, tanto no período de antecipação quanto para acusar ciclos inexistentes ou não acusar ciclos que ocorreram na série principal.

O IPC-M apresenta o mesmo número de turning-points que a série de referência, em um total de dez. Destes, dois são antecipados no longo prazo. Entretanto, das cinco recessões na produção industrial, apenas duas foram acompanhadas pela série em questão. A série do IPA apresenta apenas três períodos de contração, porém os mesmos ocorrem conjuntamente com a série de referência e a antecipação, no longo prazo, de três pontos de inflexão. A taxa de juros Selic apresenta o mesmo número de contrações que a economia gaúcha. Porém, seu ciclo tem um comportamento contrário à série de referência, com períodos de expansão menores que os períodos de contração. No total, antecipa dois pontos de inflexão com antecedência de longo prazo.

Também é possível classificar algumas das séries componentes em uma categoria secundária de "razão econômica". Exemplos disso são as séries de inflação e taxa de juros, já que estas possuem um componente de expectativa. No caso das primeiras, na hipótese de expectativas racionais, os agentes tendem a antecipar movimentos da economia, principalmente na oferta de moeda, e isso se reflete no nível de preço. No caso das taxas de juros, também há um componente de expectativa, já que no atual modelo vigente no Brasil a taxa básica da economia é fixada pelo Comitê de Política Monetária com base na sua expectativa de atividade econômica futura ${ }^{21}$.

Morais (2009) selecionou quatro séries como indicadores antecedentes de atividade industrial no estado. Entretanto, apenas uma coincide com os apontados aqui, que é a taxa de juros. As outras três, a produção de metalurgia não ferrosos, vendas de ônibus e pessoal ocupado na indústria de São Paulo, não apresentaram

21 Neste ponto é interessante destacar que no processo de tomada de decisão do COPOM utilizamse indicadores antecedentes, tanto de atividade econômica quanto de inflação, exemplo disso é o trabalho de Chauvet (2000). 
resultados significativos no presente estudo. Ressalta-se que isso pode estar sendo influenciado pela periodicidade no processo de investigação, que em Morais (2009) foi trimestral.

\subsection{O Indicador Antecedente Composto para o Rio Grande do Sul}

A partir do processo de identificação das séries antecedentes, o próximo passo é a agregação das mesmas para formar o indicador antecedente composto. Nesse artigo são feitas três diferentes agregações contemplando as 10 séries antecedentes selecionadas. Na primeira ${ }^{22}$ estão apenas as séries de médio prazo, doravante denominado CLI-CP. Uma segunda agregação é feita apenas com séries componentes de longo prazo (CLI-LP) e, por fim, uma terceira agregação combinando séries dos dois tipos (CLI-CP+LP).

Para obter o melhor desempenho possível, diversas combinações foram feitas em cada grupo de indicadores, onde cada um dos CLIs representa a média ponderada fixa das séries componentes do mesmo. As diferentes agregações estão descritas no Quadro 4.

Quadro 4 - CLIs e suas séries componentes

\begin{tabular}{|c|c|c|}
\hline Grupo & CLI & Séries componentes \\
\hline \multirow{4}{*}{ Grupo 01-CP } & CLI-CP 01 & S006, S011, S022, S066, S067, S093, S145 \\
\cline { 2 - 3 } & CLI-CP 02 & S011, S066, S093 \\
\cline { 2 - 3 } & CLI-CP 03 & S006, S011, S022, S066, S093, S145 \\
\cline { 2 - 3 } & CLI-CP 04 & S011, S066, S093, S145 \\
\hline \multirow{2}{*}{ Grupo 02- LP } & CLI-LP 01 & S098, S100 \\
\cline { 2 - 3 } & CLI-LP 02 & S098, S100, S138 \\
\hline \multirow{2}{*}{ Grupo 03- CP+LP } & CLI-CP+LP 01 & S006, S011, S022, S066, S093, S145, S100 \\
\cline { 2 - 3 } & CLI-CP+LP 02 & S006, S011, S022, S066, S093, S145, S138 \\
\hline
\end{tabular}

Fonte: Elaboração própria.

É possível verificar que foram montados quatro CLIs de médio prazo (CLICP 01, CLI-CP 02, CLI-CP 03 e CLI-CP 04), dois de longo prazo (CLI-LP 01 e CLILP 02) e duas combinações de séries de médio e longo prazo (CLI-CP+LP 01 e CLI-CP+LP 02). Nos Gráficos 3 e 4, estão traçados os resultados obtidos para os CLIs, onde as áreas sombreadas representam as recessões da série de referência de acordo com as datações do algoritmo de Bry-Boschan.

Os indicadores de médio prazo foram os que melhor aderência demonstraram, sendo que o CLI-CP 03 conseguiu antecipar sete dos nove pontos de inflexão

22 Nessa etapa, são utilizadas as séries corrigidas pela sazonalidade, sem tendência cíclica e normalizadas, seguindo proposta da $\operatorname{OECD}(2008 \mathrm{a} ; 2008 \mathrm{~b})$. 
que a série de referência apresentava. Entretanto todos os indicadores de médio prazo apresentaram um problema, que foi a indicação de um ciclo inexistente entre os anos de 2002 e 2003. Neste ponto, o menos sensível foi o indicador CLI-CP 02.

Gráfico 3 - CLIs e as recessões no RS - médio prazo

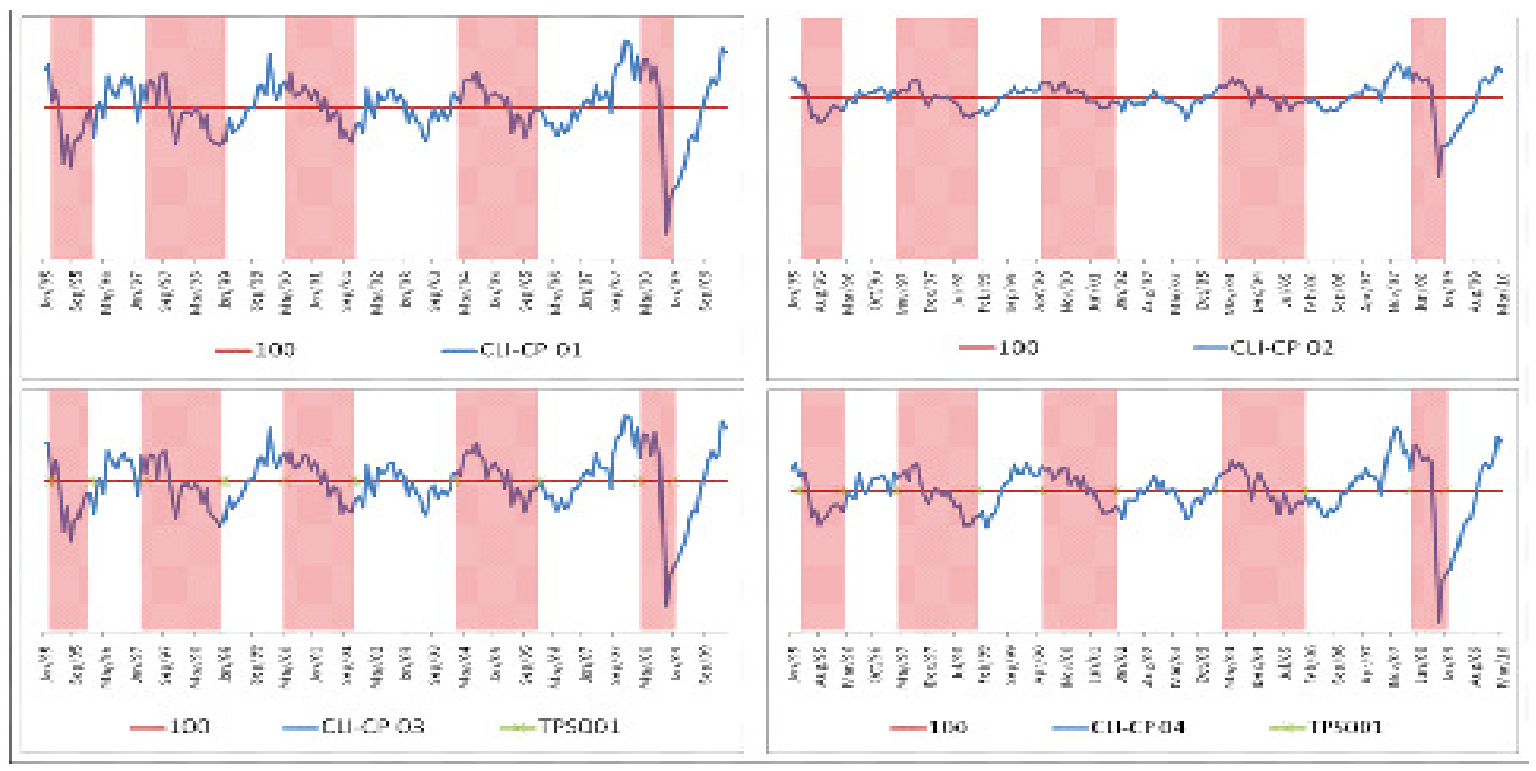

Fonte: Elaboração própria.

Os indicadores de longo prazo apresentaram maior instabilidade, tanto quanto o número de ciclos apresentados quanto ao período de antecipação dos mesmos. O que obteve melhor resultado foi o CLI-LP-02, porém o mesmo acusou dois ciclos inexistentes. Em alguns turning-points, ambos os indicadores de longo prazo anteciparam pontos de inflexão que, na verdade, deveriam ser de médio prazo.

Essas características dos indicadores de longo prazo foram transmitidas para os indicadores mistos, que contemplam aqueles de médio e longo prazo. Entretanto, nesse caso, a maior estabilidade dos indicadores de médio prazo acabou por suavizá-las. Nesta categoria, o que melhor desempenho obteve foi o indicador CLI-CP+LP 01, antecipando oito dentre os nove pontos de inflexão da série de referência e apresentando um comportamento semelhante ao CLI-CP 03. Esta forte semelhança pode estar refletindo o fato de que a diferença entre esses dois indicadores é apenas a série S100. Porém, apesar de ser considerado eficiente, esse indicador também indicou um ciclo inexistente entre 2002 e 2003. 
Gráfico 4 - CLIs e as Recessões no RS - Longo Prazo e Mistos

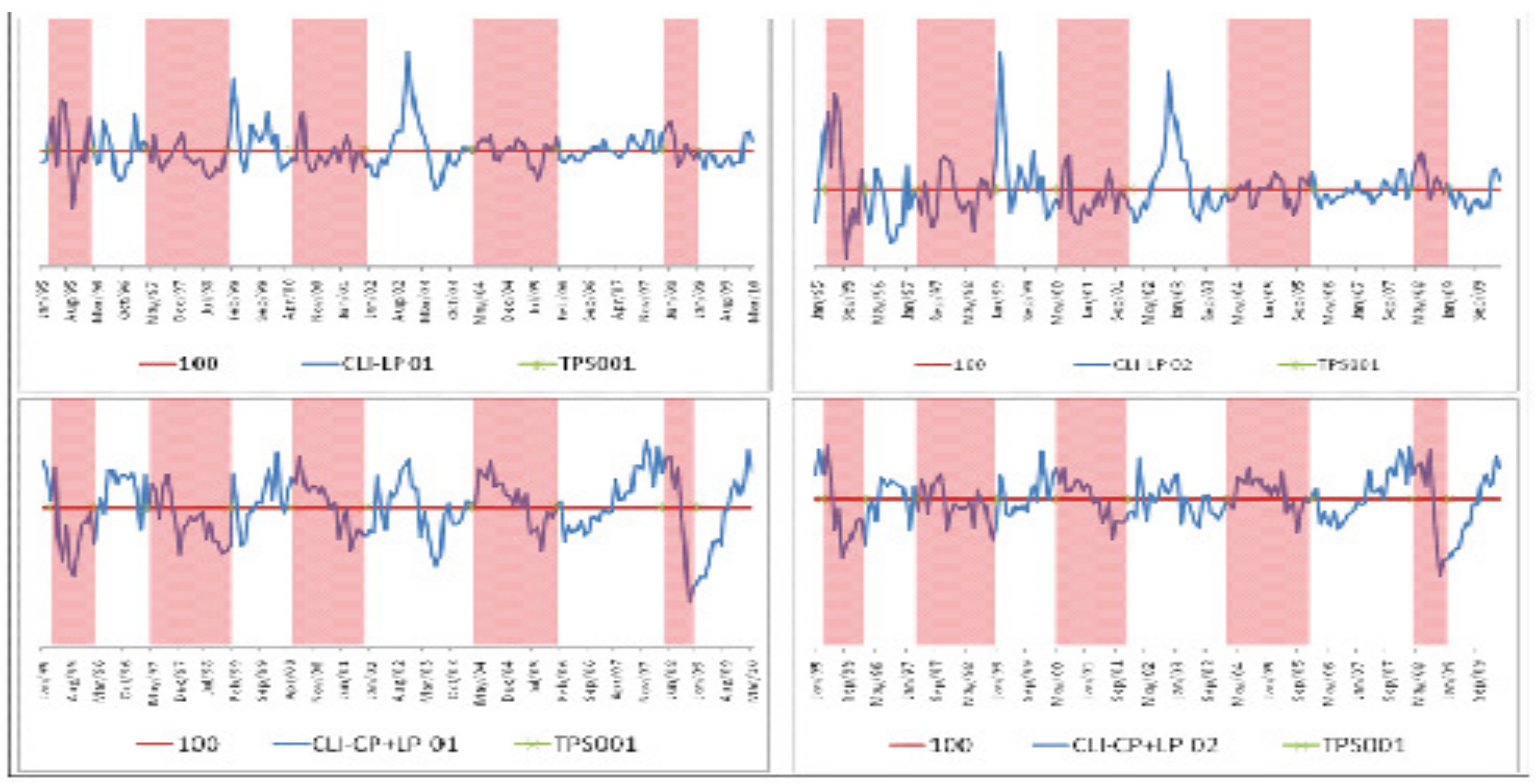

Fonte: Elaboração própria.

Para uma análise mais aprofundada do desempenho de cada CLI utilizouse uma regra de bolso. Primeiramente, identificaram-se os períodos em que os indicadores estavam acima ou abaixo da tendência de longoprazo, aqui representada pelo valor 100. Nesta classificação apenas considerou-se que o indicador alterava de patamar quando três observações seguidas assim indicavam. A seguir, os valores mais altos, quando o indicador se encontrava acima da tendência, eram datados como picos e os valores mais baixos, quando o CLI estava abaixo da tendência, eram datados como vales.

A regra também foi aplicada para identificar "falsos-picos" (e vales). Por exemplo, uma vez que o CLI esteja acima da tendência e qualquer observação for seguida por três observações menores então, considera-se a indicação de um pico. Porém, este pico pode não ser verdadeiro caso a série continue acima da tendência e apresente outra observação maior que o pico anterior e seja sucedido de três menores, o que resultará em novo pico. Essa avaliação é importante para a utilização do CLI, uma vez que o usuário pode intuir que a atividade econômica iniciou um período de retração erroneamente. $\mathrm{O}$ mesmo raciocínio foi aplicado, de maneira inversa, para os vales. A Tabela 3 sumariza os resultados. 
Tabela 3 - Desempenho dos CLIs

\begin{tabular}{ccccc}
\hline CLI & $\begin{array}{c}\text { Média de } \\
\text { antecipação } \\
\text { (em meses) }\end{array}$ & Ciclos perdidos & $\begin{array}{c}\text { Falsos turning } \\
\text { points }\end{array}$ & $\begin{array}{c}\text { Ciclos } \\
\text { adicionais }\end{array}$ \\
\hline CP-01 & 2,3 & 3 & 6 & 1 \\
CP-02 & 1,8 & 4 & 7 & 1 \\
CP-03 & 3,6 & 2 & 3 & 1 \\
CP-04 & 2,1 & 4 & 3 & 1 \\
LP-01 & 2,3 & 4 & 6 & 4 \\
LP-02 & 5,2 & 3 & 1 & 2 \\
CP+LP-01 & 5,3 & 1 & 2 & 1 \\
CP+LP-02 & 2,4 & 3 & 5 & 1 \\
\hline
\end{tabular}

Fonte: Elaboração própria.

Os resultados apresentados corroboram a primeira análise, demons-trando que o indicador de médio prazo com melhor resultado foi o CLI-CP-03, com uma média de antecipação de 3,6 meses. Além disso, teve dois ciclos "perdidos", ou seja, não antecipados, três falsos turning points e apontando um ciclo inexistente. Por outro lado, o CLI que apresenta melhor desempenho na previsão e estabilidade é o indicador misto CLI-CP+LP-01. O mesmo antecipa os turning points em média com 5,3 meses da antecedência, além de apresentar o melhor desempenho nos outros critérios de avaliação.

\section{Considerações Finais}

Este estudo demonstrou ser possível a construção de indicadores antecedentes de atividade econômica para regiões, como o Estado do Rio Grande do Sul, utilizando a metodologia da OCDE. Durante a análise, os resultados também sugeriram que, pelos resultados dos testes de correlação cruzada e causalidade de Granger, a extração da tendência cíclica a partir do filtro HP apresentou vantagens em relação ao filtro CF por conseguir melhor representar os movimentos cíclicos das diversas séries candidatas a antecedentes.

A série da produção industrial do Estado mostrou-se bastante útil para representar o ciclo dos negócios. A partir de diversos filtros estatísticos aplicados, foram selecionadas dez séries com características de anteceder esses ciclos, e que guardam característica econômica interessantes, podendo as mesmas serem divididas em dois períodos, indicadores de médio e longo prazo.

A construção dos indicadores compostos foi feita com base na média ponderada. Nesse caso, os indicadores antecedentes de médio prazo apresentaram estabilidade satisfatória para a previsão dos ciclos de negócios. A evidência também 
sugere que é possível construir indicadores com um horizonte de previsão maior. Contudo, neste caso, os mesmos não apresentaram a mesma estabilidade dos indicadores de médio prazo.

Como sugestão de pesquisa futura, uma alternativa para validar o processo de agregação das séries é a utilização de outros métodos. Para validação dos CLIs produzidos no estudo, também poder-se-ia utilizar um modelo Logit, com foco na previsão. No futuro, quando a série de atividade econômica do Rio Grande do Sul (IBCR-RS) possuir mais observações será possível reproduzir o estudo para construir indicadores ainda mais aderentes à economia local.

\section{Referências}

AGUIRRE, A. R.; CÉSPEDES, L. F. C. Uso de Análisis Factorial Dinámico para Proyecciones Macroeconómicas. Economía Chilena, Santiago de Chile, v. 7, n. 3, nov. 2004.

ALTISSIMO, F. et al. New Eurocoin: Tracking Economic Growth in Real Time. Review of Economics and Statistics, Cambridge, US, v. 92, n. 4, p. 1024-1034, Oct. 2010.

BURNS, A. F.; MITCHELL, W. C. Measuring Business Cycles. New York: NBER, 1946.

BRY, G.; BOSCHAN, C. Cyclical Analysis of Time Series: Selected Procedures and Computer Programs. New York: NBER, 1971.

CAMPELO, A. M. C. Indicadores Antecedentes de Atividade Industrial no Brasil. Rio de Janeiro: FGV, 2008.

CAULliRAUX, D. A. Uma proposta de Indicadores Coincidentes, Antecedentes e Defasados para a Indústria da Construção Civil Brasileira. Rio de Janeiro: IBMEC, 2007.

CHAUVET, M. Leading Indicators of Inflation for Brazil. Working Paper Series, Brasília, n. 7, p. 1-48, Sep. 2000. Jan./Mar. 2002.

The Brazilian Business and Growth Cycles. RBE, Rio de Janeiro, v. 56, n. 1, p. 75-106,

CHAUVET, M.; MORAIS, I. A. C. Indicadores Antecedentes para a Indústria de Bens de Capital. 2009. Disponível em: <http://bibliotecadigital.fgv.br/ojs/index.php/bre/article/ viewFile/3630/2283 > . Acesso em: 20 maio 2010.

COGLEY, T.; NASON, J. M. Effects of the Hodrick-Prescott Filter on Trend and Difference Stationary Time Series: Implications for Business Cycle Research. Journal of Economic Dynamics and Control, Amsterdam, NL, v.19, n. 2, p. 253-278, Jan./Feb.1995.

CROUX, C.; FORNI, M.; REICHLIN, L. A Measure of Comovements for Economic Indicators: Theory and Empirics. The Review of Economics and Statistics, Cambridge, US, v. 83, n. 2, p. 232-241, May 2001.

DIEBOLD, F. X.; RUDEBUSCH, G. D. Measuring Business Cycles: A modern perspective. Review of Economics and Statistics, Cambridge, US, v. 78, n. 1, p. 67-77, Feb. 1996.

ESTRELLA, A. Extracting Business Cycle Fluctuations: What do time series filters really do? Staff Report, New York, n. 289, Jun. 2007. 
FORNI, M. et al. Coincident and Leading Indicators for the EURO Area. The Economic Journal, Cambridge, GB, v. 111, n. 471, p. 62-85, Apr. 2001

GALLARDO, A. M.; PEDERSEN, M. Un Sistema de Indicadores Líderes Compuestos para La Región de América Latina. Santiago de Chile: CEPAL, 2007.

HAMILTON, J. D. A New Approach to the Economic Analysis of Nonstationary Time Series and the Business Cycle. Econometrica, Chicago, v. 57, n. 2, p. 357-384, Mar. 1989.

. Analysis of Time Series Subject to Changes in Regime. Journal of Econometrics, Amsterdam, NL, v. 45, n. 1-2, p. 39-70, Jul./Ago.1990.

A quasi-Bayesian Approach to Estimating Parameters for Mixtures of Normal Distributions. Journal of Business and Economic Statistics, Washington, US, v. 9, n. 1, p. 27-39, Jan. 1991.

. Specification Testing in Markov-Switching Time Series Models. Journal of Econometrics, Amsterdam, NL, v. 70, n. 1, p. 127-157, Jan. 1996.

LIMA, I. C. Ciclos Econômicos e Previsão Cíclica: Um Estudo de Indicadores Antecedentes para a Economia Brasileira. Belo Horizonte: Ed. da UFMG, 2005.

MILAS, C.; ROTHMAN, P.; DIJIK, D.V. Nonlinear Times Series Analysis of Business Cycles. Amsterdam, NL: Elsevier, 2006.

MITCHELL, W. C. Os Ciclos Econômicos e suas Causas. 3. ed. São Paulo: Nova Cultural, 1988.

MORAIS, I. A. C. A Crise e o Ciclo na Indústria do Rio Grande do Sul. In: MORAIS, I. A. C.; HINGEL, R. R. (Org.). A Crise Econômica Internacional e os Impactos no Rio Grande do Sul. Viamão: Entremeios, 2009. Vol. 1, p. 125-154.

MORAIS, I. A. C.; FRAINER, V. Uma investigação sobre o ciclo dos negócios na indústria da Bahia. Revista Econômica do Nordeste, Fortaleza, v. 36, n. 3, p. 378-410, 2005.

MORAIS, I. A. C.; MASSUQUETTI, A.; NESS, M. Ciclos econômicos na América Latina 19502007. In: ENCONTRO NACIONAL DE ECONOMIA, 38., Foz do Iguaçu, 2009. 1973-2009: 37 Anos de Encontros Acadêmicos. Foz do Iguaçu: ANPEC, 2009.

MORAIS, I.A.C.; PORTUGAL, M. S. Business Cycle in the Industrial Production of Brazilian States. Análise Econômica, Porto Alegre, v. 26, n. 50, p.1-20, set. 2008.

MOORE, G. H; ZARNOWITZ, V. The Development and Role of the National Bureau's Business Cycles Chronologies. Cambridge: NBER, 1984.

NILSSON, R.; BRUNET, O. Composite leading Indicators for Major OECD non-member economies: Brazil, China, India, Indonesia, Russian, South Africa. OECD Statistics Working Paper, Paris, p. 5-10, Mar. 2006.

NILSSON, R.; GYOMAI, G. Cycle Extraction. Paris: OECD, 2008a.

OECD System of Composite Leading Indicators. 2008a. Disponível em: <http://www. oecd.org/dataoecd/26/39/41629509.pdf> . Acesso em: 20 maio 2010.

Handbook on Constructing Composite Leading Indicators: Methodology and User Guide. Paris: OECD, 2008b.

SPACOV, A. D. Índices Antecedentes e Coincidentes da Atividade Econômica Brasileira: Uma Aplicação da Análise de Correlação Canônica. 2001. Dissertação (Mestrado em Econo- 
mia) - Escola de Pós-Graduação em Economia, Fundação Getúlio Vargas, Rio de Janeiro, 2001.

STOCK, J.H.; WATSON, M.W. A New Approach to Leading Economic Indicators. Harvard University, Kennedy School of Government, 1988. (mimeo).

New Indexes of Leading and Coincident Economic Indicators. In: NBER Macroeconomic Annual, Cambridge, US, v. 4, p. 351-95, Mar. 1989.

A probability Model of the Coincident Economic Indicators. In: LAHIRI, K.; $\overline{\mathrm{MOOR}}$, G (Ed.). Leading Economic Indicators: New Approaches and Forecasting Records. New York: Cambridge University Press, 1991.

A Procedure for Predicting Recessions with Leading Economic Indicators: Econometric Issues and Recent Experience. In: STOCK, J. H.; WATSON, M. W. (Ed.). New Research on Business Cycles, Indicators and Forecasting. Chicago: University of Chicago Press, 1993. p. 255-284.

Business Cycle Fluctuations in US Macroeconomic Time Series. NBER Working Paper Series, Cambridge, US, n. 6528, Apr. 1998.

Understanding Changes in International Business Cycle Dynamics. NBER Working Paper, Cambridge, US, n. 9859, Jul. 2003.

Understanding changes in international business cycle dynamics. Journal of European Economic Association, Washington, US, v. 3, n. 5, p. 968-1006, Sep. 2005.

. Business Cycles Indicators Handbook. New York: The Conference Board: 2000.

TELES, V. K. et al. Ciclos Econômicos e Métodos de Filtragem: Fatos Estilizados para o Caso Brasileiro. EconomiA, Brasília, v. 6, n. 2, p.291-328, jul./dez. 2005.

ZARNOWITZ, V. Recent Work on Business Cycles in Historical Perspective: Review of Theories and Evidence. Cambridge: NBER, 1984.

Theory and History Behing Business Cycles: are the 1990s the Onset of a Golden Age? Cambridge: NBER, 1999. 2001

. Business Cycles: Theory, History, Indicators and Forecasting. Cambridge: NBER,

ZARNOWITZ, V.; OZYILDIRIM, A.; SCHAITKIN, B. Business Cycles in the Euro Area Defined with Coincident Economic Indicators and Predicted with Leading Economic Indicator. New York: The Conference Board, 2008. 


\section{Anexo Estatístico A}

Pontos de Inflexão Antecedentes

Tabela 4 - Séries e pontos antecedentes em relação aos picos

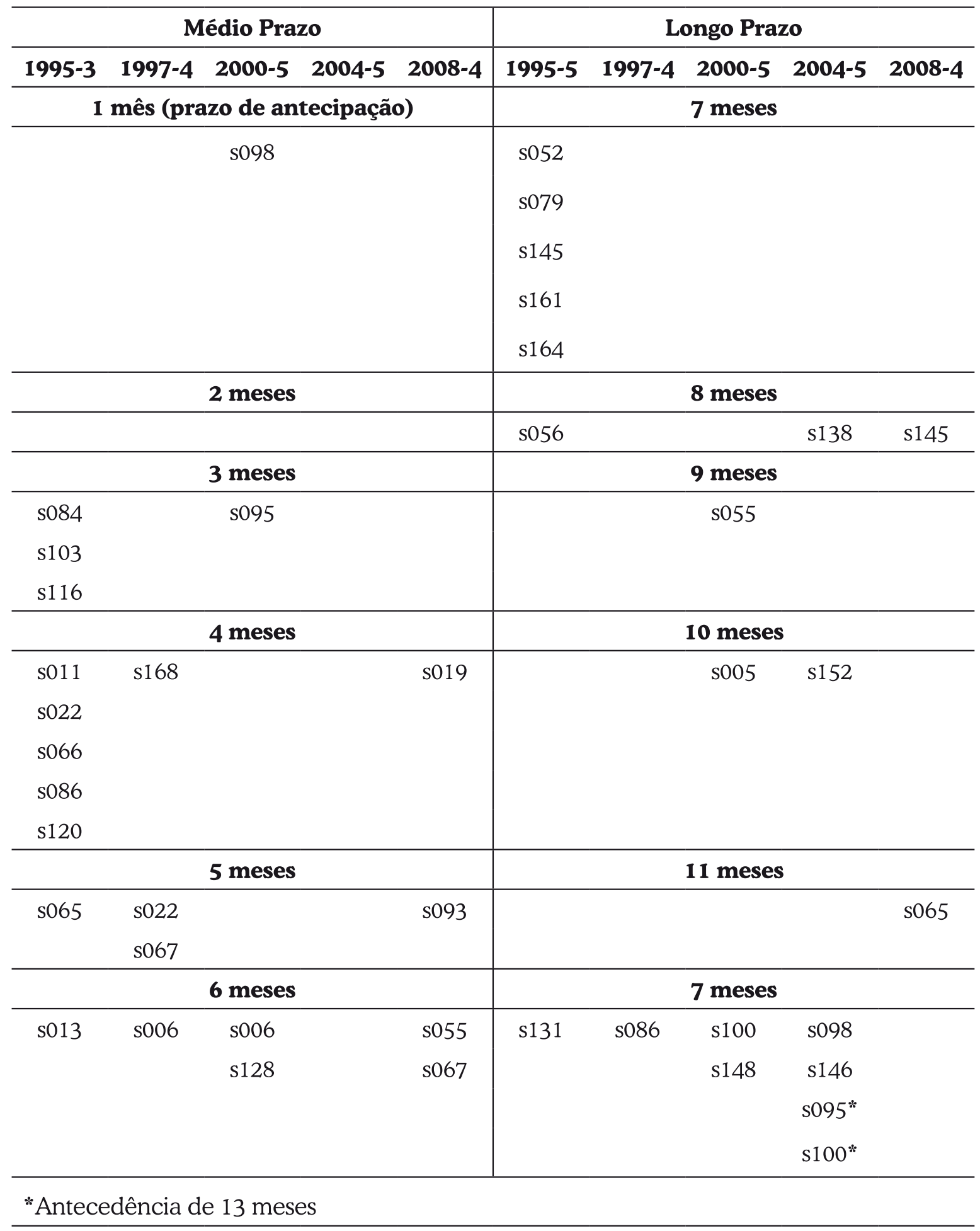

SANDRIN, R.; MORAIS, I. A. C. Indicadores Antecedentes para o Rio Grande do Sul. 


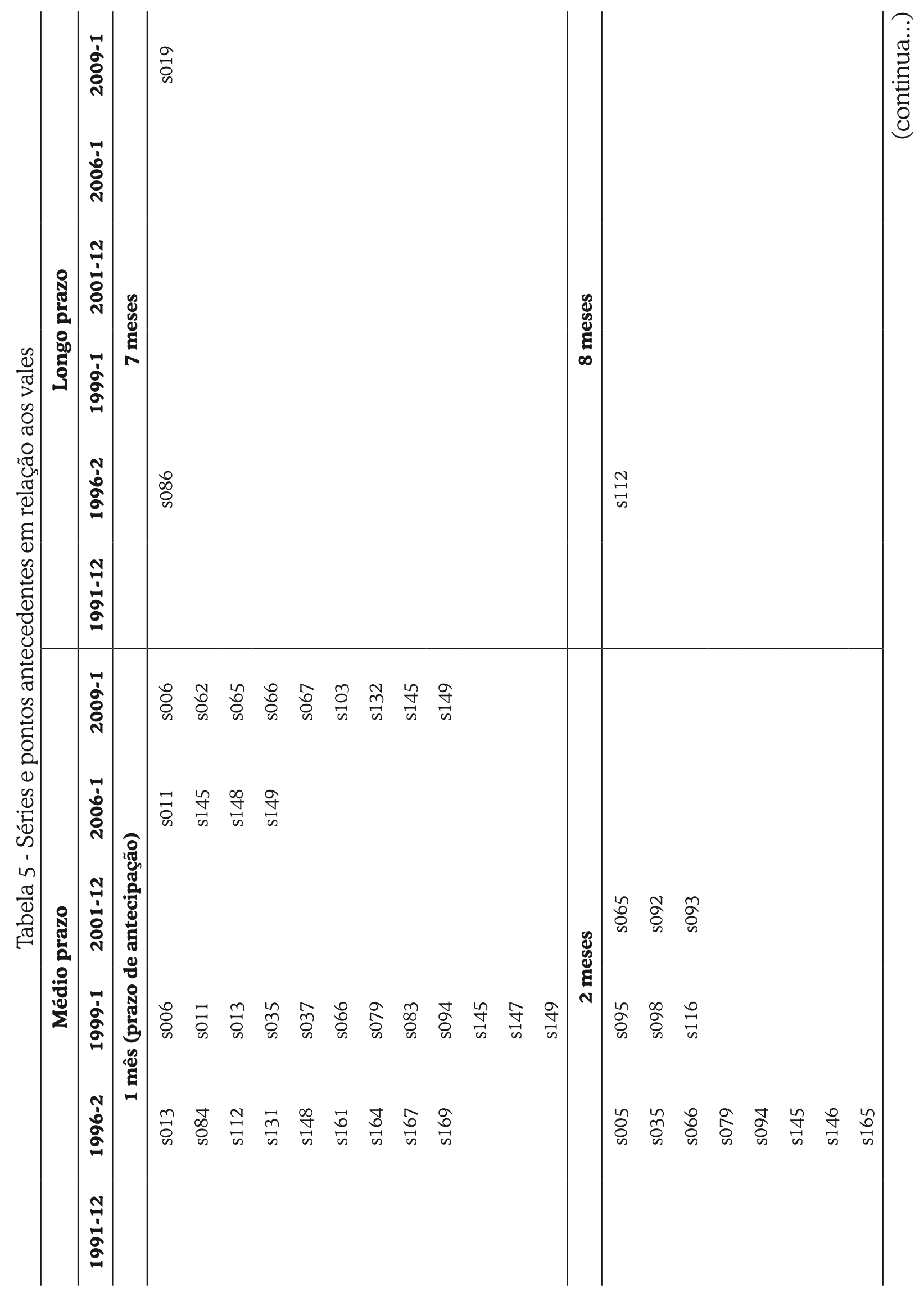




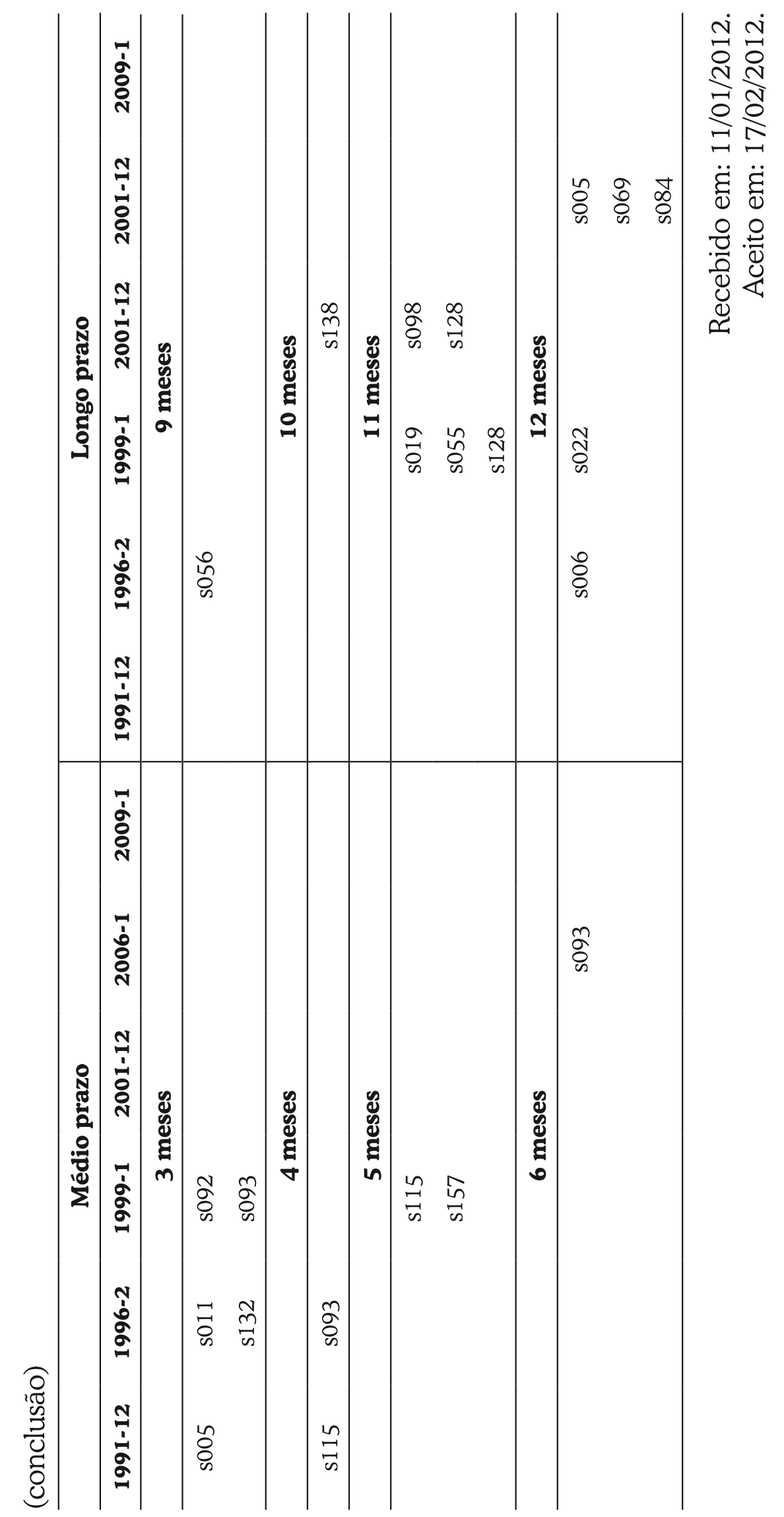

